\title{
Formulation design and evaluation of a self-microemulsifying drug delivery system of lovastatin
}

\author{
URVASHI GOYAL ${ }^{1}$ \\ RITIKA ARORA ${ }^{2}$ \\ GEETA AGGARWAL ${ }^{2 *}$ \\ 1 Rayat Institute of Pharmacy \\ Railmajra, S.B.S. Nagar, Punjab \\ India-144533 \\ 2 Rayat and Bahra Institute of Pharmacy \\ Sahauran, Kharar, District mohali \\ Punjab, India-140104
}

Accepted May 14, 2012

\begin{abstract}
Self-microemulsifying drug delivery system (SMEDDS) of lovastatin was aimed at overcoming the problems of poor solubility and bioavailability. The formulation strategy included selection of oil phase based on saturated solubility studies and surfactant and co-surfactant screening on the basis of their emulsification ability. Ternary phase diagrams were constructed to identify the self-emulsifying region. Capryol 90 (20\%) as oil, Cremophore RH40 (40\%) as surfactant and Transcutol P (40\%) as co-surfactant were concluded to be optimized components. The prepared SMEDDS was characterized through its droplet size, zeta potential, emulsification time, rheological determination and transmission electron microscopy. The optimized formulation exhibited $94 \%$ in vitro drug release, which was significantly higher than that of the drug solution. In vivo studies using the Triton-induced hyperlipidemia model in Wistar rats revealed considerable reduction in lipid levels compared to pure lovastatin. The study confirmed the potential of lovastatin SMEDDS for oral administration.
\end{abstract}

Keywords: lovastatin, SMEDDS, phase diagram, hyperlipidemia

Lovastatin (LOV) belongs to the class of cholesterol lowering drugs and is the first clinically used statin. It is a prodrug which lowers the cholesterol level through reversible competitive inhibition of 3-hydroxy-3-methyl-glutaryl coenzyme A (HMG-CoA) reductase, an enzyme involved in biosynthesis of cholesterol. It is available as conventional and extended release tablets, but its low aqueous solubility $\left(4 \times 10^{-4} \mathrm{mg} \mathrm{mL}^{-1}\right)$ finally escorts it to low oral bioavailability (less than $5 \%$ ). In addition, it undergoes extensive first pass metabolism; as a consequence of hepatic extraction it leads to low and variable availability of the drug to the general circulation. Therefore improvement in aqueous solubility of LOV is the foremost aim $(1,2)$.

\footnotetext{
* Correspondence; e-mail: geeta285@yahoo.co.in
} 
Previous researchers have made attempts to improve the aqueous solubility of LOV by preparing solid-lipid nanoparticles (1), solid dispersions using modified locust bean gum as carrier (3), methylated beta-cyclodextrin (4) complex and floating microspheres (5). Self-microemulsifying formulation of LOV was reported in literature but was not accompanied with pharmacodynamic support (2). There is a necessity to develop a formulation that would offer rapid dissolution of LOV and improve its bioavailability and finally therapeutic efficacy.

Lipid-based formulation approaches, predominantly the self-microemulsifying drug delivery system (SMEDDS), illustrate their potential as alternative approaches for the delivery of hydrophobic drugs. Dosing of drug substances that exhibit poor water solubility but sufficient lipophilic properties in a predissolved state are advantageous in view of the fact that the energy input allied with a solid-liquid phase transition is circumvented, thus overcoming the slow dissolution process after oral intake. SMEDDS formulations are isotropic mixtures of an oil, a surfactant, a co-surfactant (solubilizer) and a drug $(6,7)$.

LOV is a Biopharmaceutical Classification System (BCS) Class II drug with its low daily oral dose (10-40 mg) and high $\log P$ (octanol/water) of 4.3 providing strong justification to develop SMEDDS of LOV. The main objective of the study is to develop and evaluate an optimal SMEDDS formulation containing LOV by using Capryol 90 as oil and Cremophor RH 40/Transcutol P as surfactant/co-surfactant and to assess its pharmacodynamic outcome in lipid lowering.

\section{EXPERIMENTAL}

\section{Chemicals}

Lovastatin (LOV) and polyethoxylated castor oil (Capryol $\left.{ }^{\circledR} 90\right)$ were a kind gift from Ranbaxy Lab. Ltd. (India). Propylene glycol monocaprylate (Cremophor ${ }^{\circledR}$ RH 40), caprylcaproyl macrogol glycerides (Labrasol ${ }^{\circledR}$ ) and diethylene glycol monoethyl ether (Transcutol $^{\circledR} \mathrm{P}$ ) were donated by Gattefosse (India). Triton, castor oil, olive oil, propylene glycol, Span 80 and ethanol were purchased from S.D. Fine Chemicals (India). All other chemicals used were of analytical grade.

\section{Preliminary studies}

Screening of oil. - The solubility of LOV in different oils (Capryol 90, olive oil, castor oil and oleic acid) was determined by the shake flask method in order to screen out the oil possessing good solubilizing capacity for LOV. An excess amount of LOV was added to a vial containing $500 \mathrm{mg}$ of each oil. After sealing, the mixture was vortexed using a vortex mixer for $10 \mathrm{~min}$ in order to facilitate proper mixing of LOV with the vehicle. Mixtures were kept for $72 \mathrm{~h}$ at ambient temperature to attain equilibrium and centrifuged at $3000 \mathrm{rpm}$ for $15 \mathrm{~min}$. Aliquots of supernatant were filtered through a membrane filter $(0.45 \mu \mathrm{m})$ and diluted with mobile phase. Drug was quantified directly by using a UV-VIS spectrophotometer (Shimadzu-1700, Japan) at $\lambda_{\max } 238 \mathrm{~nm}$. 
Screening of surfactant. - Emulsification ability of various surfactants (Cremophor RH 40, Labrasol, Span 80) was screened. Surfactant (300 mg) was added to of the selected oily phase $(300 \mathrm{mg})$. The mixture was gently heated at $40-45{ }^{\circ} \mathrm{C}$ for 30 seconds to attain homogenization of components. The mixture, $50 \mathrm{mg}$, was weighed and diluted with doubly distilled water to $50 \mathrm{~mL}$ to obtain a fine emulsion. The ease of emulsion formation was scrutinized by counting the number of volumetric flask inversions to give a uniform emulsion and were observed visually for relative turbidity. The resulting emulsions were allowed to stand for $2 \mathrm{~h}$ and transmittance was observed at $638 \mathrm{~nm}$. The surfactant forming a clear emulsion with fewer inversions and higher transmittance was selected (8).

Screening of co-surfactant. - Various co-surfactants (Transcutol P, propylene glycol, ethanol) were screened for SMEDDS formulation. The screening of co-surfactants was conducted on the basis of percent transparency and ease of emulsification. Mixtures of $100 \mathrm{mg}$ of co-surfactant, $200 \mathrm{mg}$ of selected surfactant and $300 \mathrm{mg}$ of selected oil phase were prepared and evaluated in the same manner as described in the above section on surfactant screening (8).

Drug-excipient interaction. - Fourier transform infra red analysis (FTIR) of pure LOV and a mixture of LOV with excipients (mixture of surfactant and cosurfactant and oil phase) was carried out for qualitative compound identification and for drug-excipient interaction studies. LOV and mixtures were analysed using a Perkin Elmer 1600 spectrophotometer (RXIFT-IR system, USA). All samples were scanned for absorbance over the range from $4000-400 \mathrm{~cm}^{-1}$.

\section{Ternary phase diagram}

On the basis of solubility and emulsification studies, Capryol 90, Cremophor RH 40 and Transcutol P were chosen as oil, surfactant and co-surafactant, respectively. To determine the concentration of SMEDDS components that resulted in maximum microemulsion existence area, pseudoternary phase diagrams were constructed employing the water titration method at ambient temperature $\left(25^{\circ} \mathrm{C}\right)(9)$. Mixtures of surfactant and co-surfactant $\left(\mathrm{S}_{\text {mix }}\right)$ in different ratios by mass $(1: 1,1: 2,2: 1)$ were prepared. All the mixtures were mixed with oil in different ratios of 1:9, 2:8, 3:7, 4:6, 5:5, 6:4, 7:3, 8:2 and 9:1 with a total mass of $1 \mathrm{~g}$. The prepared mixtures were vortexed and then titrated with water dropwise using a microsyringe under gentle agitation. After each addition, mixtures were observed visually (turbid or clear). Percent of components at which a clear mixture was formed was figured out by constructing a pseudoternary phase diagram using the PCP disso software (Bharati Vidyapeeth University, Pune, India).

\section{Formulation of SMEDDS}

From the ternary phase diagram, the ratio of surfactant to co-surfactant was optimized. Then, by varying the ratio of oil to optimized ratio of surfactant to co-surfactant, different formulations were prepared with and without drug. Oil was added to the mixture of surfactant and co-surfactant in ratios (2:8, 2.5:7.5, 3:7, 3.5:6.5, 4:6, 4.5:5.5, 5:5, 5.5:4.5 and 6:4); these formulations were then vortexed for 5-10 min with a vortex shaker until a clear solution was obtained. 
U. Goyal et al:: Formulation design and evaluation of a self-microemulsifying drug delivery system of lovastatin, Acta Pharm. 62 (2012) 357-370.

\section{Characterization of SMEDDS}

Droplet size and polydispersity index (PDI). - Droplet size analysis and PDI measurement were carried out by dynamic light scattering with a Zetasizer HSA 3000 (Malvern Instruments Ltd, UK). All samples were subjected to sonication prior to droplet size and PDI determination.

Zeta potential. - SMEDDS formulations (F21-23) optimized from the droplet size and PDI estimation were determined using a Zetasizer HSA 3000. These formulations were subjected to sonication diluted with excess (100 times) double distilled water and then analysed.

Drug content. - LOV was extracted from the optimised preweighed SMEDDS formulation and dissolved in $25 \mathrm{~mL}$ of methanol. The extract was analysed spectrophotometrically against the standard methanolic solution of LOV.

Emulsification time. - Emulsification time of the SMEDDS formulation optimised on the basis of droplet size was assessed on a USP (10) type II dissolution apparatus (Electrolab, India). Optimized formulation $(800 \mathrm{mg}$ ) was added dropwise to $500 \mathrm{~mL}$ of distilled water maintained at $37 \pm 0.5^{\circ} \mathrm{C}$. Gentle agitation was provided by a standard stainless steel dissolution paddle rotating at $50 \mathrm{rpm}$. The emulsification time was assessed visually.

Transmission electron microscopy (TEM). - The SMEDDS of LOV (F22) was dispersed in water turning it into a microemulsion; the sample was negatively stained and the morphology of the microemulsion was photographed using a transmission electron microscope (Hitachi H7500, Japan) and the droplet size was observed.

In vitro release. - In vitro release of LOV from SMEDDS was assessed by the dialysis bag method. LOV microemulsion was instilled into the dialysis bag, firmly sealed with clamp, and placed in $500 \mathrm{~mL}$ of dissolution medium (phosphate buffer $\mathrm{pH} 6.8$ ) at $37^{\circ} \mathrm{C}$. The revolution speed of the paddle was maintained at $100 \mathrm{rpm}$. At predetermined time intervals, $5 \mathrm{~mL}$ of release medium was collected and the same volume of fresh dissolution medium was replenished to maintain the sink conditions. Concentration of LOV was analysed with a UV-VIS spectrophotometer. All the studies were conducted in triplicates.

Rheological analysis. - SMEDDS (1 mL) was optimised from the zeta potential and in vitro release studies, i.e., F22 was subjected to viscosity determination. It was diluted 10 times and 100 times with distilled water and then viscosity was measured using a Brookfield viscometer (Amkette Analytics Ltd, Mumbai, India) and assessed visually for any phase separation.

\section{In vivo pharmacodynamic studies}

Male Wistar rats (weighing $250 \pm 30 \mathrm{~g}$ ) were obtained from the Central Animal House facility of the Rayat Institute of Pharmacy, Railmajra, Punjab, India. Experimental protocols were approved by IAEC (Institutional Animal Ethics Committee) as per guidelines of the Committee for the Control and Supervision of Experiments on Animals (CPCSEA), Government of India. Animals were acclimatized in the animal house and 
were fed normal diet and water ad libitum. Overnight fasted rats were employed in the study. $250 \mathrm{mg} \mathrm{kg}^{-1}$ Triton WR 1339 (i-octyl-polyoxyethylene phenol) dissolved in $0.9 \%$ saline was administered orally to induce hyperlipidemia.

Wistar rats were divided into six groups, each containing six animals. The first group was kept as normal control. The second group was given lovastatin suspension only. Animals of the other four groups were subjected to Triton-induced hyperlipidemia; after $3 \mathrm{~h}$, the third group served as control, i.e., with Triton and no drug, the fourth group was administered a placebo formulation of SMEDDS (without drug), fifth group was administered LOV suspension $\left(2.5 \mathrm{mg} \mathrm{kg}^{-1}\right)$ in $0.5 \%$ carboxymethyl cellulose (CMC), and the sixth group was given optimised SMEDDS formulation of LOV (F22) with the same dose as given in fifth group $\left(2.5 \mathrm{mg} \mathrm{kg}^{-1}\right)$. Blood samples were withdrawn at time zero and after 24 hours of drug treatment. Serum was separated by centrifugation at 10,000 $g$ and used for biochemical analysis. Samples were analysed for total cholesterol, HDL, LDL and triglycerides using in vitro diagnostic kits (Ensure Biotech, India). Briefly, set volumes of sample and standard were mixed with the working reagent separately, followed by incubation at $37^{\circ} \mathrm{C}$ for $10 \mathrm{~min}$. Absorbance of the developed colour was read spectrophotometrically for cholesterol, HDL and triglyceride determination. From the values of total cholesterol, HDL and triglyceride, plasma LDL contents were determined (11). Lipid profiles were estimated in all groups of rats.

\section{Stability}

LOV SMEDDS (F22) was tightly sealed in a vial for storage under different storage conditions (refrigerated $4{ }^{\circ} \mathrm{C} / 75 \% \mathrm{RH}$ ), real time (room temperature) storage $\left(30{ }^{\circ} \mathrm{C} / 75 \%\right.$ $\mathrm{RH})$ and accelerated $\left(40{ }^{\circ} \mathrm{C} / 75 \% \mathrm{RH}\right)$ according to ICH (12) guidelines for one month. The stability was assessed by analysing the physical appearance, droplet size and drug content at day $0,7,15,21$ and 30 .

\section{Statistical analysis}

All the results were expressed as mean \pm SD ( $n=3$ for in vitro studies and $n=6$ for in vivo studies). The statistical analysis was performed using Students $t$-test and ANOVA followed by the Tukey test.

\section{RESULTS AND DISCUSSION}

An important consideration when formulating a self microemulsifying formulation is avoidance of drug precipitation upon dilution in gut lumen (in vivo). Therefore the components used in the system should have high solublisation capacity for the drug (2). Different oils were screened for LOV solublisation, among which Capryol 90 showed the highest solubility $\left(32.0 \pm 0.2 \mathrm{mg} \mathrm{mL}^{-1}\right)$ while other oils accommodated approximately 10-20 mg mL -1 of LOV. Hence, Capryol 90 was selected as an oil phase. Amongst various surfactants, selection was done on the basis of ease of emulsification and higher transmittance (8). The results revealed that Cremophore RH40 showed $99 \%$ transmittance and 8 inversions, whereas Labrasol and Span 80 showed $69 \%$ and $64 \%$ transmit- 
tance and 44 and 81 inversions, respectively. In case of the co-surfactants screened, Transcutol P showed $89 \%$ transmittance and 45 inversions compared to propylene glycol and ethanol with 87 and $88 \%$ transmittance and 50 and 122 inversions, respectively. Thus Cremophore RH 40 was selected as the surfactant and Transcutol P as co-surfactant.

The FTIR spectra of pure LOV and formulation F22 are shown in Fig. 1. The spectrum of pure LOV showed characteristic peaks at $3541 \mathrm{~cm}^{-1}$ (alcohol O-H stretching), $3015 \mathrm{~cm}^{-1}$ (olefinic C-H stretching), $2965 \mathrm{~cm}^{-1}$ (methyl C-H asymmetric stretching), $2929 \mathrm{~cm}^{-1}$ (methylene C-H asymmetric stretching), $2866 \mathrm{~cm}^{-1}$ (methyl and methylene $\mathrm{C}-\mathrm{H}$ asymmetric stretching), 1725, $1699 \mathrm{~cm}^{-1}$ (lactone and ester carbonyl stretch), $1459 \mathrm{~cm}^{-1}$ (methyl asymmetric bend), $1381 \mathrm{~cm}^{-1}$ (methyl symmetric bend), $1262 \mathrm{~cm}^{-1}$ (lactone C-O-C asymmetric bend), $1220 \mathrm{~cm}^{-1}$ (ester C-O-C asymmetric bend), $1073 \mathrm{~cm}^{-1}$ (lactone C-C symmetric bend), $1055 \mathrm{~cm}^{-1}$ (ester C-O-C symmetric bend), $970 \mathrm{~cm}^{-1}$ (alcohol C-OH stretch) and $870 \mathrm{~cm}^{-1}$ (trisubstituted olefinic C-H). From Fig. 1, it was observed that there were no significant changes in the position of characteristic peaks of the drug when mixed with oil, surfactant and co-surfactant, which indicated compatibility of excipients and the drug.

Phase diagrams were constructed to figure out the maximum microemulsion area with optimisation of the best ratio of surfactant and co-surfactant (1:1, 1:2 and 2:1) and composition of excipients for developing optimal SMEDDS. The purpose was to arrive at a composition that contained minimum amount of surfactant and co-surfactant without compromising its globule size and stability (9). From Fig. 2, it was observed that the mixture of surfactant and co-surfactant in ratio 1:1 showed the maximum microemulsion area; therefore this was selected as the optimal ratio.

Composition of all the formulations with different ratios of oil to the optimised ratio of surfactant and co-surfactant (1:1), with or without drug, is shown in Table I. After preparation, the formulations were subjected to physicochemical characterisation including droplet size and polydispersity index (PDI), zeta potential, viscosity and transmission electron microscopy.

Droplet size is a crucial factor in self-emulsification performance, because it determines the rate and extent of drug release as well as drug absorption. It has been reported that small size of emulsion droplets may lead to more rapid absorption, thereby improving the bioavailability (13). Furthermore, a decrease in the droplet size reflects the formation of a better packed film of the surfactant at the oil-water interface, thereby stabilising the oil droplets (14). PDI is the ratio of standard deviation to mean droplet size, which signifies uniformity of droplet size within the formulation. The higher the value of PDI, the lower is the uniformity of droplet size. Results revealed that formulations F22 to F28 solubilised the therapeutic dose of LOV, but among these formulations F25 and F26 had droplet size larger than $50 \mathrm{~nm}$ as well as higher PDI of $0.37 \pm 0.26$ and $0.30 \pm$ 0.24 , respectively. Formulations F27 and F28 had lower PDI of $0.28 \pm 0.28$ and $0.26 \pm 0.28$ but droplet size larger than $50 \mathrm{~nm}$, while formulations F22, F23 and F24 followed the criteria of microemulsion by having the droplet size lower than $50 \mathrm{~nm}$ as well as lower PDI of $0.15 \pm 0.15,0.21 \pm 0.20$ and $0.26 \pm 0.21$, respectively, indicating the uniformity of particles as shown in Table I. Hence, formulations F22 to F24 were selected for further evaluation studies.

It has been reported in the literature that an increase in repulsive forces between microemulsion droplets prevents their coalescence (14). Zeta potential of the selected 
U. Goyal et al.: Formulation design and evaluation of a self-microemulsifying drug delivery system of lovastatin, Acta Pharm. 62 (2012) 357-370.
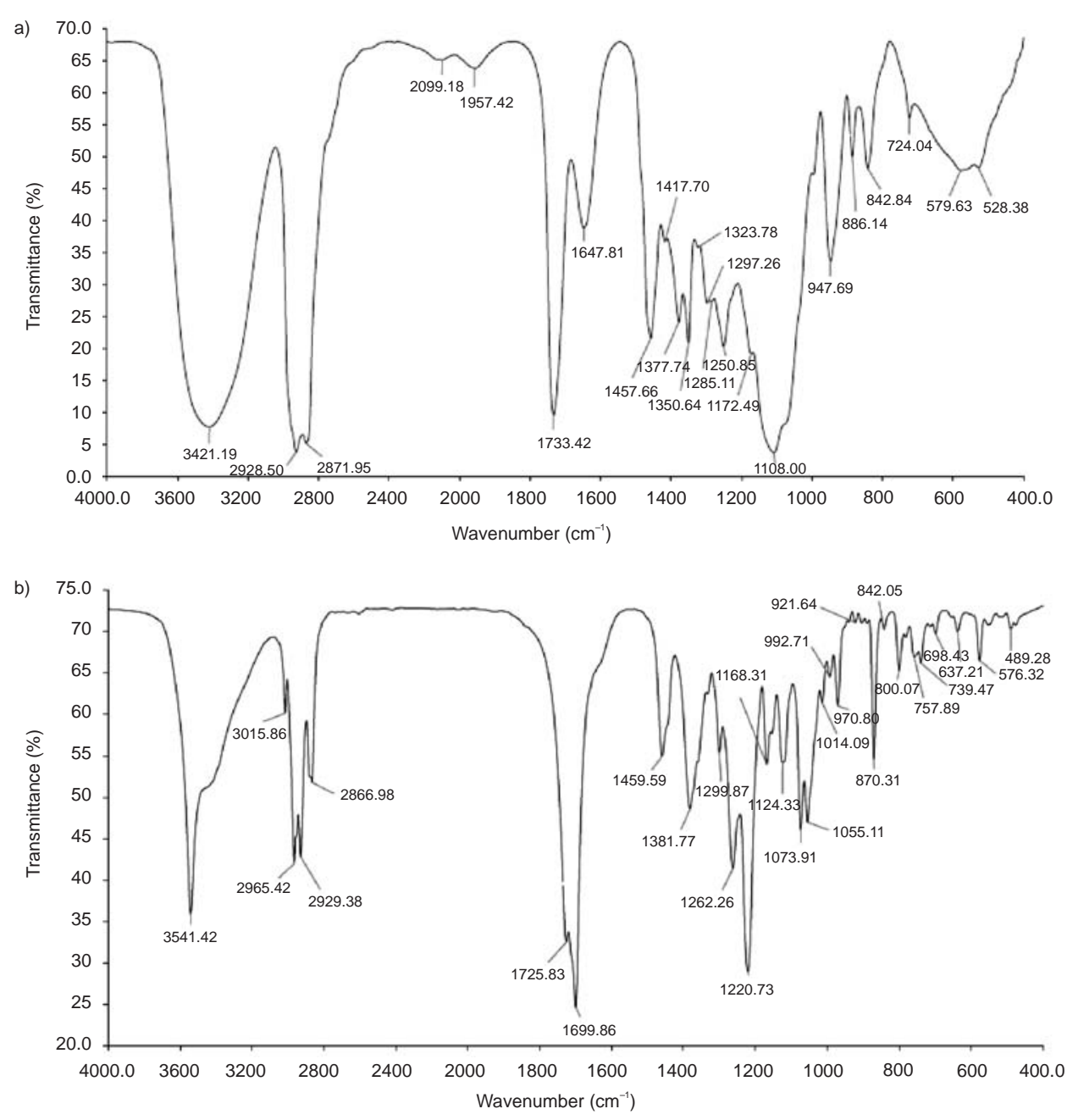

Fig. 1. FTIR Spectra of: a) pure lovastatin and b) lovastatin $(20 \mathrm{mg})$ with $800 \mathrm{mg}$ of a mixture of Cremophore RH 40 and Transcutol P in the ratio of 1:1 (mixture of surfactant and cosurfactant) and 200 mg of Capryol 90 (oil phase)(2 \% lovastatin).

formulations (F22, F23 and F24) when diluted 100 times was found to be $-4.56,-15.7$ and $-12.3 \mathrm{mV}$, respectively. As formulation F22 showed the highest zeta potential value, it was concluded to be more stable since coalescence between microemulsion droplets was prevented.

The drug content uniformity in the optimised formulations (F22, F23 and F24) was found in the range of $99.3 \pm 1.3$ for F22 to $99.8 \pm 1.0 \%$ for F24, indicating uniform drug dispersion in formulations. 
U. Goyal et al:: Formulation design and evaluation of a self-microemulsifying drug delivery system of lovastatin, Acta Pharm. 62 (2012) $357-370$.

Table I. Composition, droplet size and PDI of prepared SMEDDS

\begin{tabular}{|c|c|c|c|c|c|}
\hline Formulation code & $\mathrm{S}_{\text {mix }} 1: 1$ & Oil (mg) & Drug $(m g)^{b}$ & Droplet size $(\mathrm{nm})^{\mathrm{c}}$ & $\mathrm{PDI}^{\mathrm{c}}$ \\
\hline $\mathrm{F} 1^{\mathrm{a}}$ & 800 & 200 & - & $17.20 \pm 0.21$ & $0.126 \pm 0.22$ \\
\hline $\mathrm{F}^{\mathrm{a}}$ & 750 & 250 & - & $20.98 \pm 0.21$ & $0.175 \pm 0.26$ \\
\hline $\mathrm{F}^{\mathrm{a}}$ & 700 & 300 & - & $26.74 \pm 0.24$ & $0.236 \pm 0.24$ \\
\hline $\mathrm{F} 4^{\mathrm{a}}$ & 650 & 350 & - & $40.58 \pm 0.22$ & $0.337 \pm 0.22$ \\
\hline $\mathrm{F}^{\mathrm{a}}$ & 600 & 400 & - & $55.88 \pm 0.25$ & $0.275 \pm 0.25$ \\
\hline $\mathrm{F}^{\mathrm{a}}$ & 550 & 450 & - & $92.78 \pm 0.21$ & $0.255 \pm 0.21$ \\
\hline $\mathrm{F}^{\mathrm{a}}$ & 500 & 500 & - & $103.15 \pm 0.25$ & $0.235 \pm 0.25$ \\
\hline F8 & 800 & 200 & 10 & $21.25 \pm 0.24$ & $0.129 \pm 0.24$ \\
\hline F9 & 750 & 250 & 10 & $24.88 \pm 0.22$ & $0.178 \pm 0.25$ \\
\hline F10 & 700 & 300 & 10 & $30.12 \pm 0.23$ & $0.239 \pm 0.26$ \\
\hline F11 & 650 & 350 & 10 & $45.18 \pm 0.25$ & $0.341 \pm 0.28$ \\
\hline F12 & 600 & 400 & 10 & $60.57 \pm 0.24$ & $0.279 \pm 0.22$ \\
\hline F13 & 550 & 450 & 10 & $97.46 \pm 0.22$ & $0.258 \pm 0.27$ \\
\hline F14 & 500 & 500 & 10 & $108.34 \pm 0.25$ & $0.237 \pm 0.26$ \\
\hline F15 & 800 & 200 & 15 & $23.56 \pm 0.22$ & $0.134 \pm 0.20$ \\
\hline F16 & 750 & 250 & 15 & $28.89 \pm 0.21$ & $0.182 \pm 0.24$ \\
\hline F17 & 700 & 300 & 15 & $32.74 \pm 0.22$ & $0.242 \pm 0.25$ \\
\hline F18 & 650 & 350 & 15 & $48.81 \pm 0.25$ & $0.344 \pm 0.22$ \\
\hline F19 & 600 & 400 & 15 & $65.15 \pm 0.22$ & $0.285 \pm 0.26$ \\
\hline F20 & 550 & 450 & 15 & $102.18 \pm 0.17$ & $0.263 \pm 0.20$ \\
\hline F21 & 500 & 500 & 15 & $110.99 \pm 0.25$ & $0.245 \pm 0.27$ \\
\hline F22 & 800 & 200 & 20 & $42.50 \pm 0.18$ & $0.152 \pm 0.15$ \\
\hline F23 & 750 & 250 & 20 & $47.52 \pm 0.17$ & $0.208 \pm 0.20$ \\
\hline F24 & 700 & 300 & 20 & $48.68 \pm 0.20$ & $0.264 \pm 0.21$ \\
\hline F25 & 650 & 350 & 20 & $68.85 \pm 0.22$ & $0.365 \pm 0.26$ \\
\hline F26 & 600 & 400 & 20 & $81.89 \pm 0.23$ & $0.301 \pm 0.24$ \\
\hline F27 & 550 & 450 & 20 & $120.60 \pm 0.22$ & $0.278 \pm 0.28$ \\
\hline $\mathrm{F} 28$ & 500 & 500 & 20 & $128.25 \pm 0.27$ & $0.258 \pm 0.28$ \\
\hline
\end{tabular}

$\mathrm{S}_{\text {mix }}$ - mixture of Cremophore 40 (surfactant) and Transcutol P (co-surfactant) in the ratio 1:1.

a Formulations without drug (placebo formulations)

b Drug concentration 1-2 \% $(\mathrm{m} / \mathrm{m})$.

c Mean $\pm \mathrm{SD}, n=3$.

The emulsification rate is a useful index to appraise emulsification efficiency of a formulation. It has been suggested that the mechanism of self emulsification involves attrition of a fine cloud of small droplets from the surface of large droplets, instead of progressive reduction in droplet size (15). The selected formulations (F22, F23 and F24) were subjected to assessment of emulsification time. The results divulged that F22 showed 

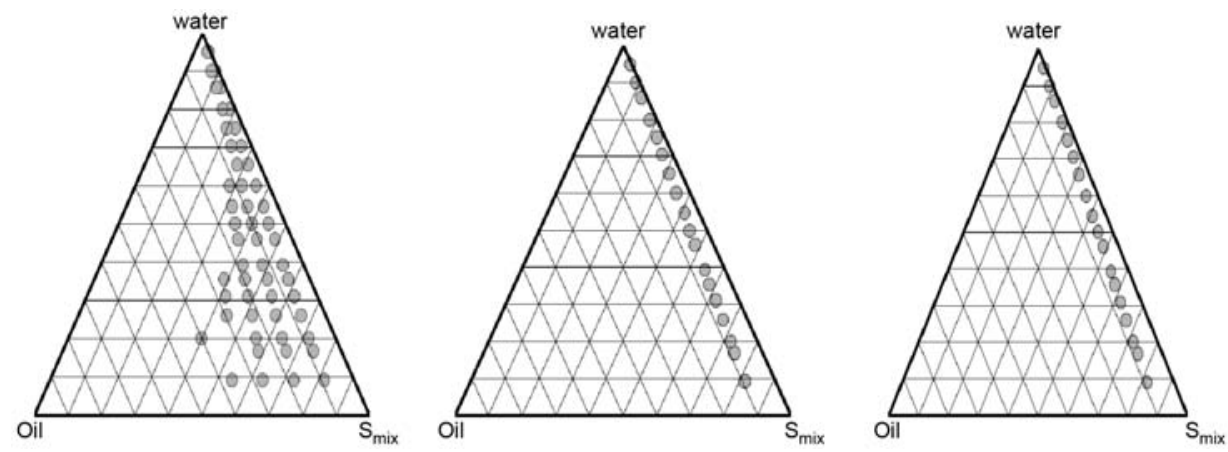

Fig. 2 Pseudoternary phase diagram of a formulation composed of oil (Capryol 90), a mixture of surfactant (Cremophore RH40) and cosurfactant (Transcutol P) dispersed with water at $37^{\circ} \mathrm{C}$. Surfactant/co-surfactant ratio: a) 1:1, b) $1: 2$ and c) $2: 1$.

minimum emulsification time of $70 \pm 1 \mathrm{~s}$ while F23 and F24 showed $188 \pm 2$ and $215 \pm 2 \mathrm{~s}$ and therefore F22 was found optimised for further evaluation.

The selected formulations F22, F23, F24 and drug solution were subjected to an in vitro dissolution study by the dialysis bag method (Fig. 3). The release profiles showed that the drug release from formulation F22 was higher than from the other formulations and significantly enhanced compared to the standard drug solution $(p<0.05)$. Factors responsible may be the small droplet size, as the smaller droplet size provides more surface area for releasing the drug from the system, thereby, increasing the drug release rate $(14,15)$. Also, the oil phase of SMEDDS may act as a carrier molecules which do not diffuse through the barrier but allow drug molecules to get diffused through the membrane of the dialysis bag (16).

When a formulation is infinitely diluted, there is a huge possibility of its phase separation, since microemulsions are formed at particular oil, surfactant and water concentrations. Therefore rheological determination was performed (15). Viscosity of the optimized SMEDDS (F22) was found to be high (40 $\left.\mathrm{mPa} \mathrm{s}, 22^{\circ} \mathrm{C}\right)$. After, 10 and 100 times di-

Fig. 3. Release profiles of drug solution and optimized SMEDDS formulations (mean \pm SD, $n=3)$.

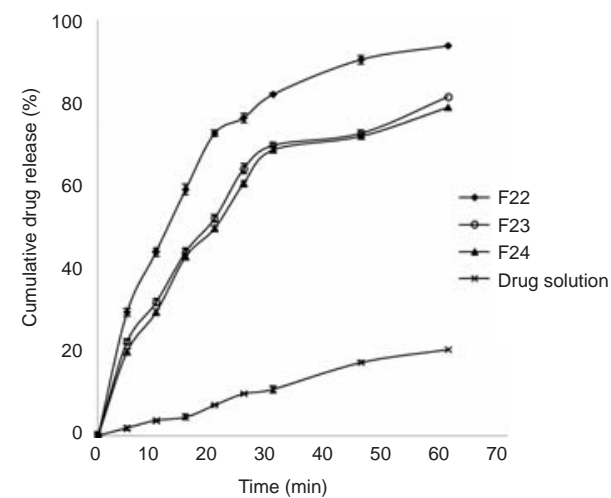


lution with distilled water, it was found to be $8 \mathrm{mPa} \mathrm{s}\left(22^{\circ} \mathrm{C}\right)$ and $4 \mathrm{mPa} \mathrm{s}\left(24^{\circ} \mathrm{C}\right)$, respectively, with no phase separation, which confirmed the stability of the formulation.

The surface morphology of SMEDDS as well as droplet size were predicted by using transmission electron microscopy. Fig. 4 shows the average droplet size of the microemulsion dispersed from formulation F22. The droplets were spherical in shape, with a size smaller than $50 \mathrm{~nm}$, which satisfies the criteria of nano size range required for microemulsifying formulations (17).

The anti-hyperlipidemic activity of LOV-loaded SMEDDS and the active pharmaceutical ingredient were evaluated by lipid lowering studies using a Triton-induced hyperlipidemia model $(8,11)$. Triton is a nonionic surfactant that induces hyperlipidemia by inhibiting peripheral lipoprotein lipase enzymes responsible for removal of lipid particles from the body. The administration of Triton leads to transient elevation of lipid levels, which reach a peak 18 to 24 hours after administration (phase I) and start to lower again the following day (phase II). For our present study, this method was used to evaluate the lipid-lowering activity of the developed formulation. The mechanism by which LOV exerts its antihyperlipidemic effect was reported stating that $\beta$-hydroxyacid, the active metabolite of LOV, lowers plasma lipids by inhibiting HMG-CoA reductase, the enzyme that catalyses the conversion of HMG-CoA to mevalonate. The conversion of HMG-CoA to mevalonate is an early step in the biosynthetic pathway for cholesterol. LOV is known to stay shorter in the blood circulation because it has a biological half-life of 1.1-1.7 hours. Thus, the effects of LOV and its formulation on serum lipid level were studied only in phase I.

From the results of pharmacodynamic studies (Fig. 5), it was observed that LOV suspension produced a drop in serum cholesterol (from 146 to $105 \mathrm{mg}$ per $100 \mathrm{~mL}$ ), tri-

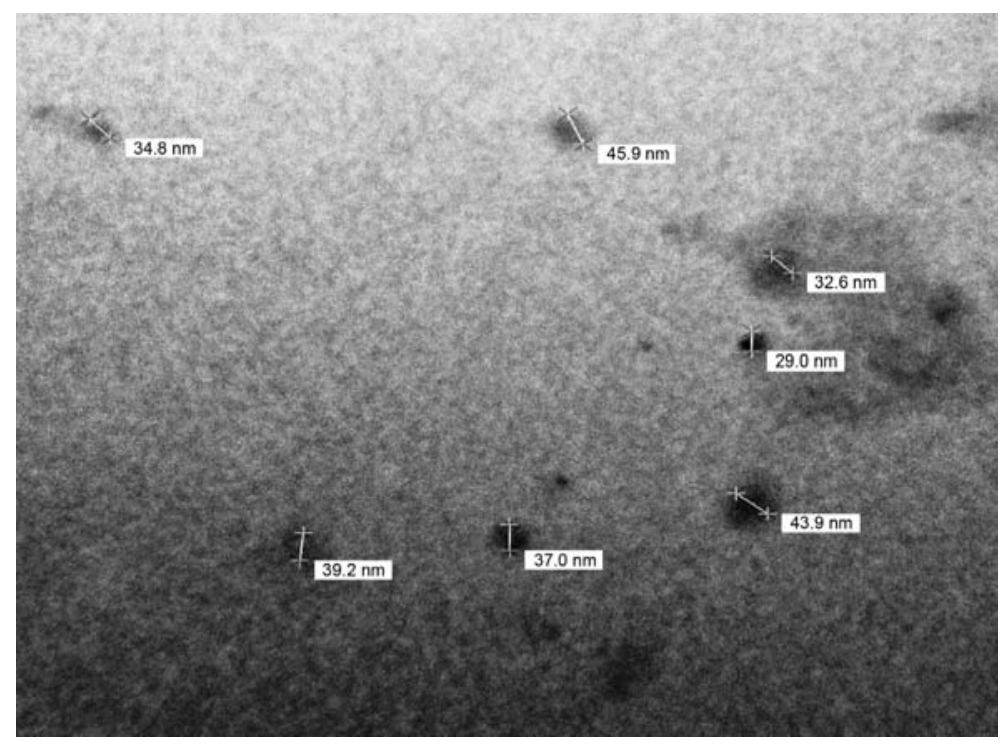

Fig. 4. TEM of lovastatin microemulsion (magnification 100,000 x). 
glyceride (from 248 to $145 \mathrm{mg}$ per $100 \mathrm{~mL}$ ), LDL (from 171 to $133 \mathrm{mg}$ per $100 \mathrm{~mL}$ ) and rise in HDL (from 15 to $26 \mathrm{mg}$ per $100 \mathrm{~mL}$ ), whereas LOV-loaded SMEDDS formulation produced a significant decrease in serum cholesterol (from 146 to $51 \mathrm{mg}$ per $100 \mathrm{~mL}$ ), triglycerides (from 248 to $117 \mathrm{mg}$ per $100 \mathrm{~mL}$ ), LDL level (from 171 to $22 \mathrm{mg}$ per $100 \mathrm{~mL}$ ) and a marked increase in HDL level (from 15 to $36 \mathrm{mg}$ per $100 \mathrm{~mL}$ ). The anti-hyperlipidemic activity of SMEDDS of LOV was significantly higher, $(p<0.05)$ than of LOV. This higher lipid lowering activity of the SMEDDS formulation can be explained by the fact that the SMEDDS formulation resulted in complete dissolution of LOV, which could have increased absorption and thereby led to higher plasma drug concentration (higher bioavailability). The low bioavailability of LOV suspension is attributed to its poor aqueous solubility. The above difference in pharmacodynamic activity and the results of in vitro dissolution studies suggest that the SMEDDS formulation resulted in higher oral bioavailability owing to higher solubilisation of LOV from the SMEDDS formulation compared to the active pharmaceutical ingredient (8).

Stability studies of the selected SMEDDS were performed at refrigerated, real time and accelerated conditions. The results of the study are presented in Table II. Student's $t$-test was used to compare the results of the sample after 7, 15, 21 and 30 days with the fresh sample. No significant changes in physical appearance, droplet size and drug content were observed after stability testing in any case. The results revealed the stability of optimised SMEDDS formulation of LOV.

a)

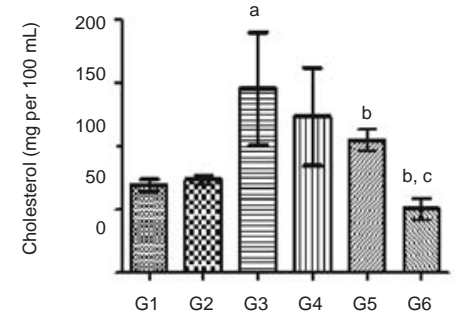

c)

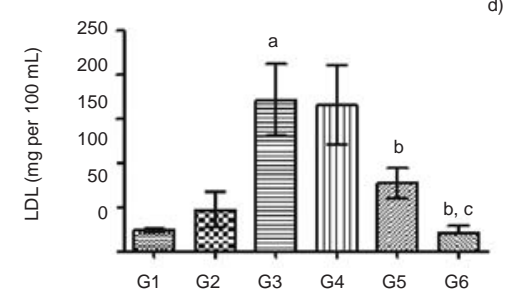

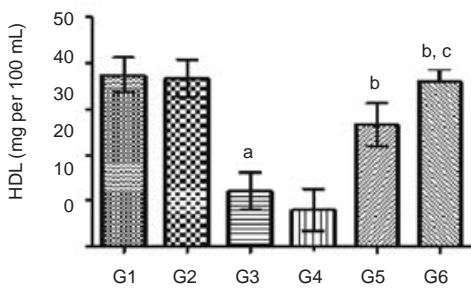

d)

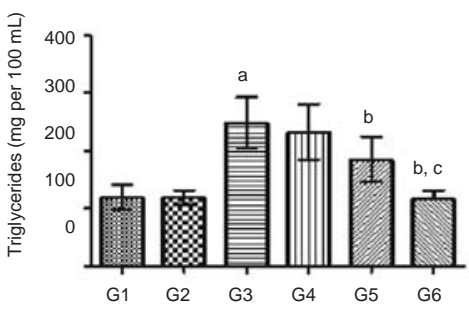

Fig. 5. Effect of SMEDDS of lovastatin on Triton-induced hyperlipidemia in rats ( $n=6$ in each group). Group 1 (G1) normal animals, group 2 (G2) animals administered lovastatin suspension $\left(2.5 \mathrm{mg} \mathrm{kg}^{-1}\right.$, in $0.5 \%$ CMC), group 3 (G3) animals administered Triton, group 4 (G4) animals given Triton and then SMEDDS with no drug (placebo), group 5 (G5) animals administered with Triton and lovastatin suspension (2.5 mg kg-1, in $0.5 \% \mathrm{CMC}$ ), and group 6 (G6) animals given Triton and lovastatin-loaded SMEDDS (F22) $2.5 \mathrm{mg} \mathrm{kg}^{-1}$. a $p<0.05$ vs. normal control, ${ }^{\mathrm{b}} p<0.05$ vs. G3, ${ }^{\mathrm{c}} p<0.05$ vs. G5. In Fig. 5, c stands for significant difference vs. groups 5 and 6. 
U. Goyal et al:: Formulation design and evaluation of a self-microemulsifying drug delivery system of lovastatin, Acta Pharm. 62 (2012) 357-370.

Table II. Stability of formulation F22 under different conditions

\begin{tabular}{|c|c|c|c|c|c|c|c|c|c|}
\hline \multirow{2}{*}{$\begin{array}{l}\text { Time } \\
\text { (day) }\end{array}$} & \multicolumn{3}{|c|}{ Refrigerated $\left(4^{\circ} \mathrm{C} / 75 \% \mathrm{RH}\right)$} & \multicolumn{3}{|c|}{ Real time $\left(30{ }^{\circ} \mathrm{C} / 75 \% \mathrm{RH}\right)$} & \multicolumn{3}{|c|}{ Accelerated $\left(40{ }^{\circ} \mathrm{C} / 75 \% \mathrm{RH}\right)$} \\
\hline & $\begin{array}{l}\text { Droplet size } \\
\qquad(\mathrm{nm})^{\mathrm{a}}\end{array}$ & PA & Drug $\left({ }^{\circ}\right.$ & $\begin{array}{l}\text { Droplet size } \\
\text { (nm) })^{\mathrm{a}}\end{array}$ & PA & Druq & $\begin{array}{l}\text { Droplet size } \\
(\mathrm{nm})^{\mathrm{a}}\end{array}$ & PA & Drug $(\%)^{\mathrm{a}}$ \\
\hline 0 & $42.5 \pm 0.3$ & + & $99.3 \pm 1.3$ & $42.5 \pm 0.2$ & + & $99.3 \pm 1.2$ & $42.5 \pm 0.3$ & + & $99.3 \pm 1.3$ \\
\hline 7 & $40.6=$ & + & 99.1 & 42.3 & + & 1.0 & 0.2 & + & 99.1 \\
\hline 15 & $41.3 \pm 0.3$ & + & $98.9 \pm .098$ & $41.2 \pm 0.3$ & + & $98.9 \pm 1.0$ & $41.7 \pm 0.3$ & + & $99.0 \pm 0.9$ \\
\hline 21 & $43.2 \pm 0.3$ & + & $98.8 \pm 0.78$ & $41.9 \pm 0.3$ & + & $98.3 \pm 0.9$ & $44.1 \pm 0.3$ & + & $98.7 \pm 0.8$ \\
\hline 30 & $42.8 \pm 0.2$ & + & $98.6 \pm 0.92$ & $43.2 \pm 0.2$ & + & $98.3 \pm 0.9$ & $43.6 \pm 0.2$ & + & $98.5 \pm 1.0$ \\
\hline
\end{tabular}

PA - Physical appearance: + - no phase separation, no flocculation, no precipitation.

Real time - room temperature conditions.

a Mean $\pm \mathrm{SD}, n=3$.

\section{CONCLUSIONS}

In the present study, the poorly water-soluble LOV was formulated into a beneficial and patient compliant self-microemulsifying system to improve its solubility and bioavailability. SMEDDS of LOV was prepared and optimized by using parameters such as droplet size, PDI, zeta potential, in vitro release data. Optimal SMEDDS consisted of Capryol 90 as the oil phase, Cremophore RH40 as surfactant and Transcutol P as co-surfactant. Permutation of all three components, i.e., oil/surfactant/co-surfactant in the ratio 20:40:40, formulates SMEDDS with particle size $42.5 \mathrm{~nm}$, PDI 0.15 and zeta potential $-4.56 \mathrm{mV}$. This optimised SMEDDS showed good in vitro release, which is increased by more than $90 \%$ when compared to pure drug solution. From pharmacodynamic studies, we concluded that the developed SMEDDS formulation of LOV shows superior lipid lowering activity compared to pure LOV. Thus our studies exemplified the promising use of the self-microemulsified drug delivery system to dispense lipid-soluble drugs by oral route.

Acknowledgements. - The authors are grateful to Central Instrumentation Lab, Panjab University, Chandigarh, India, for carrying out TEM studies and Rayat-Bahra Educational and Research Trust for providing research facilities.

\section{REFERENCES}

1. G. Suresh, K. Manjunath, V. Venkateswarlu and V. Satyanarayana, Preparation, characterization and in vitro and in vivo evaluation of lovastatin solid lipid nanoparticles, AAPS Pharm. Sci. Tech. 8 (2007) E162-E170; DOI: 10.1208/pt081024.

2. S. K. Singh, P. R. P. Verma and B. Razdan, Development and characterization of a lovastatin loaded self-microemulsifying drug delivery system, Pharm. Dev. Tech. 15 (2010) 469-483; DOI: $10.3109 / 10837450903286537$. 
U. Goyal et al:: Formulation design and evaluation of a self-microemulsifying drug delivery system of lovastatin, Acta Pharm. 62 (2012) 357-370.

3. M. Patel, A. Tekade, S. Gattani and S. Surana, Solubility enhancement of lovastatin by modified locust bean gum using solid dispersion techniques, AAPS Pharm. Sci. Tech. 9 (2008) 1262-1269; DOI: $10.1208 /$ s12249-008-9171-4.

4. A. Sule, L. Szente and F. Csempesz, Enhancement of drug solubility in supramolecular and colloidal systems, J. Pharm. Sci. 98 (2009) 484-494; DOI: 10.1002/jps.21437.

5. S. Kumar, K. Nagpal, S. K. Singh and D. N. Mishra, Improved bioavailability through floating microspheres of lovastatin, DARU J. Pharm. Sci. 19 (2011) 57-64.

6. B. K. Kang, J. S. Lee, S. K. Chon, S. Y. Jeong, S. H. Yuk, G. Khang, H. B. Lee and S. H. Cho, Development of self-microemulsifying drug delivery systems (SMEDDS) for oral bioavailability enhancement of simvastatin in beagle dogs, Int. J. Pharm. 274 (2004) 65-73; DOI: 10.1016/j. ijpharm.2003.12.028.

7. D. Patel and K. K. Sawant, Oral bioavailability enhancement of acyclovir by self-microemulsifying drug delivery system (SMEDDS), Drug Dev. Ind. Pharm. 33 (2007) 1318-1326; DOI: 10.1080/ 03639040701385527.

8. A. R. Patel and P. R. Vavia, Preparation and in vivo evaluation of SMEDDS (self-microemulsifying drug delivery system) containing fenofibrate, AAPS J. 9 (2007) E344-352; DOI: 10.1208/ aapsj0903041.

9. A. R. Dixit, S. J. Rajput and S. G. Patel, Preparation and bioavailability assessment of SMEDDS containing valsartan, AAPS Pharm. Sci. Tech. 11 (2010) 314-321; DOI: 10.1208/s12249-010-9385-0.

10. United States Pharmacopoeia 33, National Formulary 28, USP Convention, Rockville (MD) 2010.

11. P. E. Schurr, J. R. Schultz and T. M. Parkinson, Triton-induced hyperlipidemia in rats as an animal model for screening hypolipidemic drugs, Lipids 7 (1972) 68-74.

12. International Conference on Harmonization Q1A(R2) Stability Testing Guidelines: Stability Testing of New Drug Substances and Products, ICH 2003.

13. S. X. Cui, S. F. Nie, L. Li, C. G. Wang and W. S. Pan, Preparation and evaluation of self-microemulsifying drug delivery system containing vinpocetine, Drug Dev. Ind. Pharm. 35 (2009) 603-611; DOI: 10.1080/03639040802488089.

14. J. Cui, B. Yu, Y. Zhao, W. Zhu, H. Li, H. Lou and G. Zhai, Enhancement of oral absorption of curcumin by self-microemulsifying drug delivery systems, Int. J. Pharm. 371 (2009) 148-155; DOI: 10.1016/j.ijpharm.2008.12.009.

15. M. J. Patel, N. M. Patel, R. B. Patel and R. P. Patel, Formulation and evaluation of self-microemulsifying drug delivery system of lovastatin, Asian J. Pharm. Sci. 5 (2010) 266-275.

16. Y. G. Bachhav and V. B. Patravale, SMEDDS of glyburide: Formulation, in vitro evaluation and stability studies, AAPS Pharm. Sci. Tech. 10 (2009) 482-487; DOI: 10.1208/s12249-009-9234-1.

17. X. Wu, J. Xu, X. Huang and C. Wen, Self-microemulsifying drug delivery system improves curcumin dissolution and bioavailability, Drug Dev. Ind. Pharm. 37 (2011) 15-23; DOI: $10.3109 /$ 03639045.2010.489560. 
U. Goyal et al:: Formulation design and evaluation of a self-microemulsifying drug delivery system of lovastatin, Acta Pharm. 62 (2012) 357-370.

\section{$S A \check{Z} E T A K$}

\section{Dizajniranje i evaluacija samomikroemulzifikacijskog sustava za isporuku lovastatina}

URVASHI GOYAL, RITIKA ARORA i GEETA AGGARWAL

U svrhu povećanja topljivosti i bioraspoloživosti lovastatina dizajniran je i evaluiran samomikroemulzifikacijski sustav za isporuku lijeka (SMEDDS). Uljna faza izabrana je na temelju studija topljivosti, a surfaktant i kosurfaktant na temelju njihove sposobnosti emulzifikacije. Samoemulzifikacijsko područje određeno je pomoću ternarnih faznih dijagrama. Kao optimalni sastojci pokazali su se Kapriol 90 (20\%) kao uljna faza, Cremophore RH40 (40 \%) kao surfaktant i Transcutol P (40 \%) kao kosurfaktant. Pripravljenom SMEDDS određena je veličina kapljica, zeta potencijal, emulzifikacijsko vrijeme, reološka svojstva i transmisija u elektronskoj mikroskopiji. In vitro se iz optimiziranog pripravka oslobodilo $94 \%$ ljekovite tvari, što je bilo značajno više nego iz otopine lijeka. Studije in vivo na Wistar štakorima kojima je hiperlipidemija inducirana Tritonom pokazale su da SMEDDS značajno više snižava razinu lipida nego čisti lovastatin. Istraživanja su potvrdila da je lovastatin SMEDDS pripravak pogodan za peroralnu primjenu.

Ključne riječi: lovastatin, SMEDDS, fazni dijagram, hiperlipidemija

Rayat Institute of Pharmacy, Railmajra, S.B.S. Nagar, Punjab, India-144533

Rayat and Bahra Institute of Pharmacy, Sahauran, Kharar, District mohali, Punjab, India-140104 